Hydrol. Earth Syst. Sci., 10, 309-320, 2006

www.hydrol-earth-syst-sci.net/10/309/2006/

(c) Author(s) 2006. This work is licensed

under a Creative Commons License.

\title{
Vectors of subsurface stormflow in a layered hillslope during runoff initiation
}

\author{
M. Retter ${ }^{1}$, P. Kienzler ${ }^{2}$, and P. F. Germann ${ }^{1}$ \\ ${ }^{1}$ Department of Geography, University of Bern, Hallerstr. 12, 3012 Bern, Switzerland \\ ${ }^{2}$ Institute of Environmental Engineering, ETH Zürich, Schafmattstr. 8, 8093 Zürich, Switzerland
}

Received: 7 November 2005 - Published in Hydrol. Earth Syst. Sci. Discuss.: 30 November 2005

Revised: 3 February 2006 - Accepted: 9 March 2006 - Published: 10 May 2006

\begin{abstract}
The focus is the experimental assessment of insitu flow vectors in a hillslope soil. We selected a $100 \mathrm{~m}^{2}$ trenched hillslope study site. During prescribed sprinkling an obliquely installed TDR wave-guide provides for the velocity of the wetting front in its direction. A triplet of wave-guides mounted along the sides of an hypothetical tetrahedron, with its peak pointing down, produces a three-dimensional vector of the wetting front. The method is based on the passing of wetting fronts. We analysed 34 vectors along the hillslope at distributed locations and at soil depths from $11 \mathrm{~cm}$ (representing top soil) to $40 \mathrm{~cm}$ (close to bedrock interface). The mean values resulted as follows $v_{x}=16.1 \mathrm{~mm} \mathrm{~min}^{-1}$, $\boldsymbol{v}_{y}=-0.2 \mathrm{~mm} \mathrm{~min}^{-1}$, and $\boldsymbol{v}_{z}=11.9 \mathrm{~mm} \mathrm{~min}^{-1}$. The velocity vectors of the wetting fronts were generally gravity dominated and downslope orientated. Downslope direction ( $\mathrm{x}-$ axis) dominated close to bedrock, whereas no preference between vertical and downslope direction was found in vectors close to the surface. The velocities along the contours (yaxis) varied widely. The Kruskal-Wallis tests indicated that the different upslope sprinkling areas had no influence on the orientation of the vectors. Vectors of volume flux density were also calculated for each triplet. The lateral velocities of the vector approach are compared with subsurface stromflow collected at the downhill end of the slope. Velocities were 25-140 times slower than lateral saturated tracer movements on top of the bedrock. Beside other points, we conclude that this method is restricted to non-complex substrate (skeleton or portion of big stones).
\end{abstract}

Correspondence to: $\mathrm{M}$. Retter

(retter@giub.unibe.ch)

\section{Introduction}

For a wide range of hillslopes subsurface stormflow (SSF) is considered a major runoff generating process. For instance, Weyman et al. (1973) studied the direction and occurrence of the subsurface runoff component and found the following: Infiltration is driven by gravity and thus flow in slopes is dominated by vertical unsaturated movements towards the profile base, where lateral subsurface flow originates due to breaks in vertical permeability (distinct soil horizons or impermeable bedrock). They further argued that, once saturated conditions have been generated, lateral flow should occur, because the equipotential lines within the saturated soil will be nearly orthogonal to the gradient of the slope. The authors mentioned also that runoff response will be considerably delayed if water has to move first to the base of the soil profile, but lateral flow controls the magnitude of hillslope response.

Harr (1977) used tensiometer plots to closer look at the magnitude and direction of water fluxes in a hillslope. Between storms the vertical flux component at the $10 \mathrm{~cm}$-depth was less than the downslope (lateral) components, but similar during storms. Conversely, vertical flux components at the 70 - and $130 \mathrm{~cm}$-depths were inferior to the downslope components during storms but similar to downslope components between storms. Greminger (1984) calculated two-dimensional and Wheater et al. (1987) calculated threedimensional soil water fluxes from tensiometer data. They monitored lateral components during dry conditions and after high intensity rainfall. They also determined the triggering factors such as slope angle, degree of saturation, hydraulic conductivity of soil horizons, and rainfall intensity. Anderson and Burt (1978) illustrated the influence of contour curvature (three-dimensional) on moisture movement.

Published by Copernicus GmbH on behalf of the European Geosciences Union. 


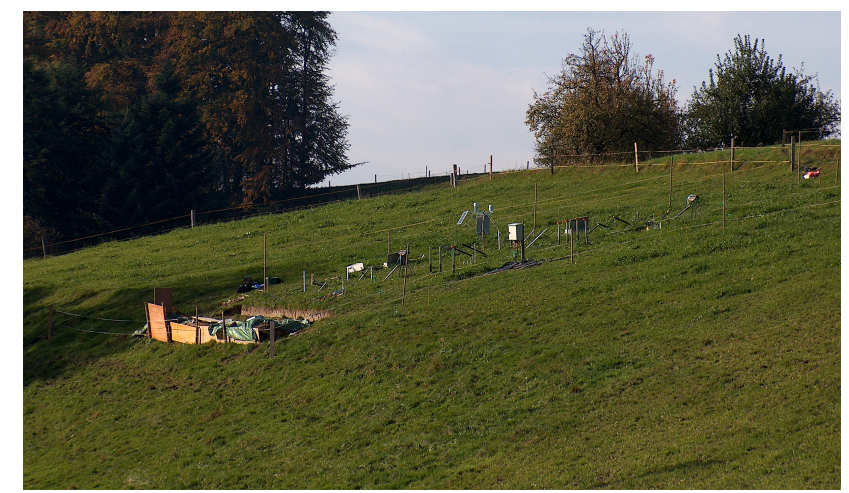

Fig. 1. The Lutertal study site on a grassland slope in northern Switzerland. Note the brownish trench face which was excavated at the bottom end of the instrumented $100 \mathrm{~m}^{2}$ plot.

Preferential flow in soil pipes occurs laterally above and within soil layers of lower permeability such as solid rocks and glacial tills or perched water tables (Sidle et al., 2000; Koyama and Okumura, 2002; Uchida et al., 2005). Beven and Germann (1982) considered infiltration, with its possible preferential flow, as driven by gravity. Buttle and McDonald (2002) investigated preferential flow systems in a thin soil at a slope by a combined approach consisting of TDR waveguides and water/solute studies. The former measurement indicated vertical infiltration whereas the latter focused on lateral flow towards a trench. Both, matrix flow and preferential flow have to bend from mainly vertical to the predominant lateral direction. However, the processes leading to the pattern are poorly understood. Sherlock et al. (2000) discussed the necessity to include the general uncertainty associated with hydrometric techniques in the subsurface (e.g. calculation of hillslope flow paths).

We present the results of an investigation on the direction of flow at the hillslope scale. We focus on the direction of the infiltration fronts that are associated with sprinkling and that lead to runoff. The objectives of this paper are:

i.) How "vertical" is vertical infiltration?

ii.) Can we find evidence for "bending of flow" from the vertical to lateral?

iii.) How does the velocity vector of the wetting front relate to runoff concentration time?

iv.) What is the potential of the setup, to improve understanding of hillslope runoff?

\section{Study site}

The hillslope site was located at Lutertal, community of Reiden, northern Switzerland. We consciously selected a site where lateral SSF is likely to occur. An illustration of the
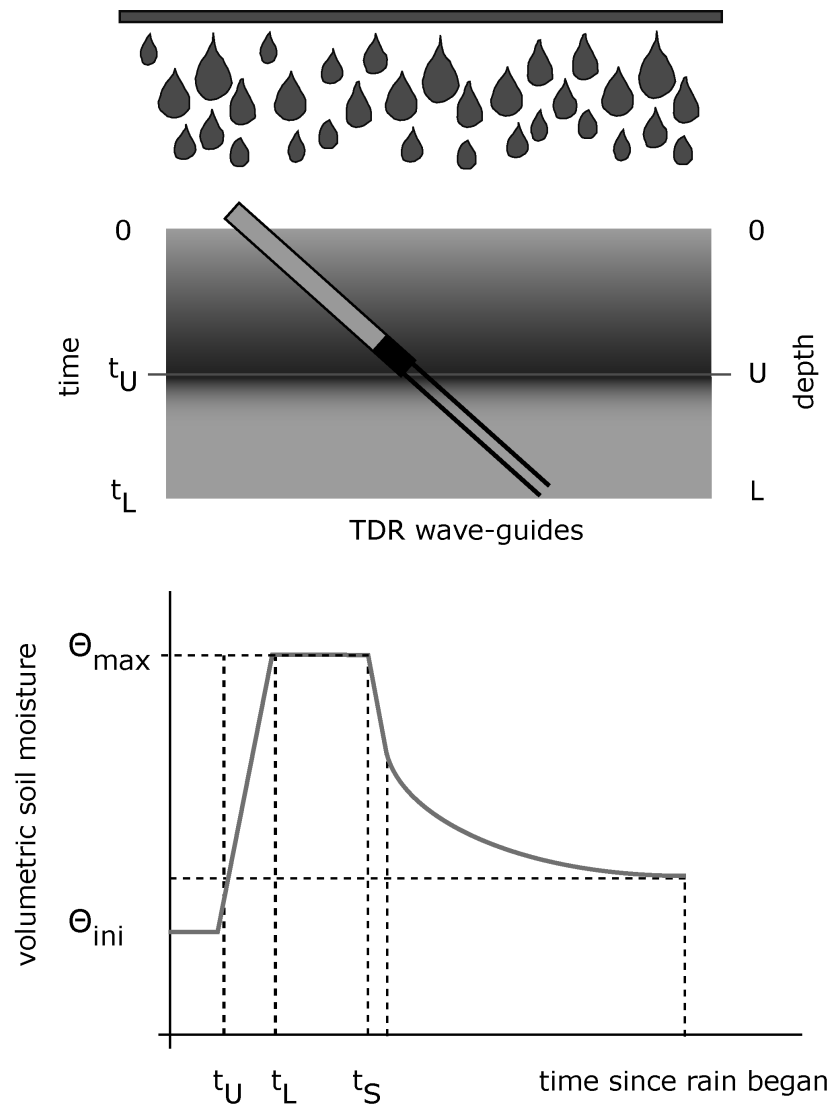

Fig. 2. Schematic representation of an obliquely installed waveguide, a downwards travelling wetting front (up) and the linear increase of $\theta$ as the wetting front moves steadily (below). $t_{S}$ indicates end of sprinkling.

study site is provided in Fig. 1. Average annual precipitation at the site is $1056 \mathrm{~mm}$. During the past 30 years the site has been under grassland. Prior to all experiments on the meadow we mowed the grass down to $5 \mathrm{~cm}$. The slope angle $\alpha$ was $13.5^{\circ}$. On it we randomly chose a $12 \times 16 \mathrm{~m}^{2}$ plot. We marked the sidewise and top borders on the surface to determine the sprinkling area of $100 \mathrm{~m}^{2}$. At the bottom end of the plot we excavated a trench down to the bedrock. The soil consisted of a top Ah-horizon $(0-8 \mathrm{~cm})$ and a sandy loam B-horizon with an average depth down to $45 \mathrm{~cm}$. The particle size distribution in the B-horizon was $20 \%$ sand, $53.1 \%$ silt, and $22.9 \%$ clay by weight. Packing density within the $25 \mathrm{~cm}$ of soil depth amounted to $2 \mathrm{~g} \mathrm{~cm}^{-3}$ and increased to $3 \mathrm{~g} \mathrm{~cm}^{-3}$ for the layer down to $40 \mathrm{~cm}$. Rooting depth of the grass was down to about $10 \mathrm{~cm}$ soil depth.

We observed vertical macropores within B-horizon at the trench face, mostly created by earthworms (Lumbricidae). Macropore density in the B-horizon was 248 per $\mathrm{m}^{2}$. Further, small lateral soil pipes (diameter 3-8 $\mathrm{mm}$ ) occurred at the transition between the B-horizon and bedrock. 


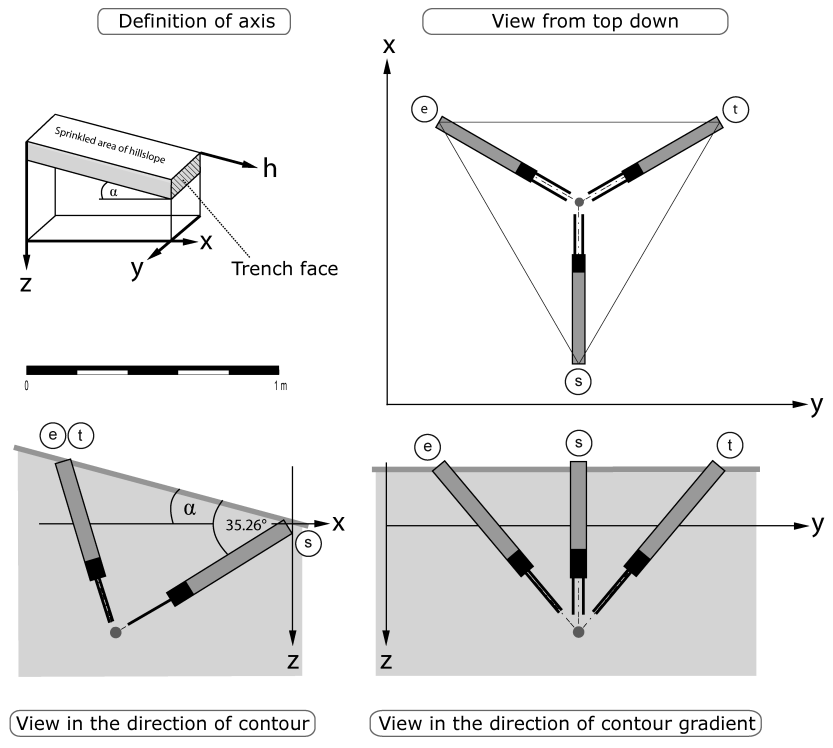

Fig. 3. Definition of axis (top left) and scheme of mounting a triplet of TDR wave-guides in a hillslope soil by its different views. Probes (black) are attached to aluminium pipes (dark grey). Note that yaxis becomes positive towards right and negative towards left. And $\mathrm{z}$-axis becomes more positive with increasing depth.

The underlying bedrock is composed of siltstone ( $\mathrm{Mo}$ lasse) with reduced hydraulic conductivity. We detached a siltstone cube by a saw and performed laboratory experiments. During sprinkling experiments (intensity $=12 \mathrm{~mm} \mathrm{~h}^{-1}$ ) onto the top surface the propagating wetting front was measured by TDR wave-guides. The velocity amounted to $1.4 \mathrm{~mm} \mathrm{~min}^{-1}$ (surface to depth of $3.5 \mathrm{~cm}$ ) and $0.16 \mathrm{~mm} \mathrm{~min}^{-1}$ (surface to depth of $9.3 \mathrm{~cm}$ ). No wetting arrived at $13 \mathrm{~cm}$ depth during $1 \mathrm{~h}$ of sprinkling (I. WillenHincapié, University of Bern, personal communication).

\section{Methods}

Germann and Zimmermann (2005a) applied a novel approach to two sprinkling experiments at the $1-\mathrm{m}^{2}$-plot scale. This is now extended to the hillslope scale.

\subsection{Basics on TDR application}

Obliquely installed TDR wave-guides record the temporal increase of volumetric soil moisture $\theta\left[\mathrm{m}^{3} \mathrm{~m}^{-3}\right]$ when the wetting front moves across. This increase between the initial volumetric soil moisture $\theta_{\text {ini }}$ and the maximum volumetric soil moisture $\theta_{\max }$ is outlined for a single TDR wave-guide in Fig. 2. In a further step, the direction of the vector component is set equal to the one of the wave-guides. The steady

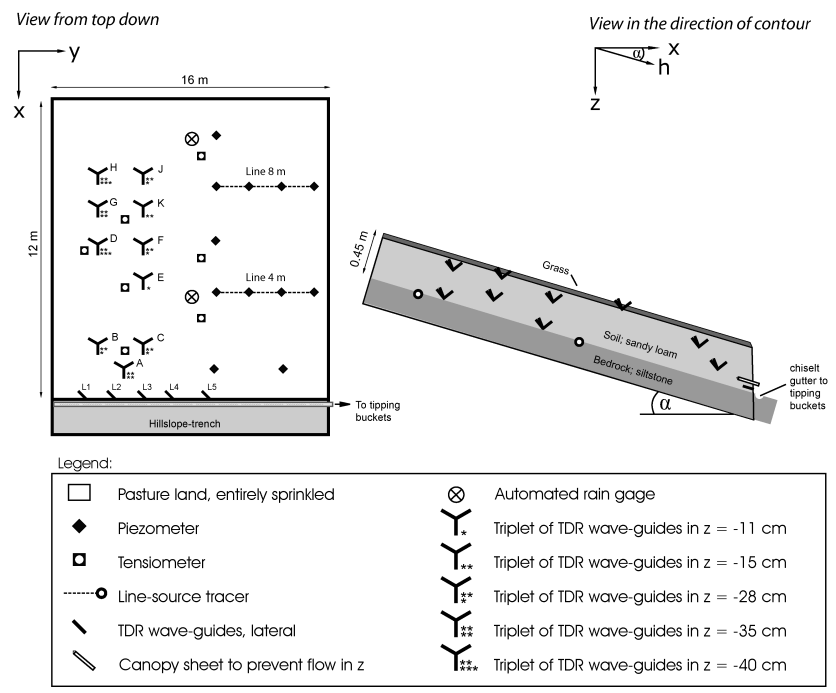

Fig. 4. Instrumentation and setup of TDR triplets on the hillslope. Left: top down view; right: view in the direction of contour (profile).

advancement of the wetting front during the interval $t_{U}$ to $t_{L}$ yields:

$\boldsymbol{v}_{i}=\frac{\boldsymbol{l}_{i}}{t_{L, i}-t_{U, i}}=\frac{\Delta \theta_{i}}{\Delta t_{i}} \cdot \frac{\boldsymbol{l}_{i}}{w_{\max _{i}}}$

where $w_{\max }=\theta_{\max }-\theta_{\text {ini }}\left[\mathrm{m}^{3} \mathrm{~m}^{-3}\right], l$ is the length of waveguides positioned between $U_{i}(x, y, z)$ and $L_{i}(x, y, z), t_{U}$ and $t_{L}$ are the arrival times of the wetting front at $U$ and $L$, and $\Delta \theta / \Delta t$ is the slope of $\theta(t)$ between $t_{U}$ and $t_{L}$. Likewise, according to Germann et al. (2002) and Germann and Zimmermann (2005b), the vector of the average volume flux density, $q\left[\mathrm{~m} \mathrm{~s}^{-1}\right]$, during $t_{U}<t<t_{L}$ in the direction of the wave guides is:

$\boldsymbol{q}_{i}=v_{i} \cdot w_{\max _{i}}=\boldsymbol{l}_{i} \cdot \frac{\Delta \theta_{i}}{\Delta t_{i}}$

The index $i \in(e, t, s)$ refers to the wave-guides, Fig. 3 . The procedure is repeated for the two other wave-guides. Figure 3 shows the installation of one triplet, containing three TDR wave-guides, which are orthogonally aligned to each other. Figures 3 and 4 show the arrangement of the wave-guides in the coordinate system. The vector sum (norm vector) is:

$\boldsymbol{v}_{\mathrm{tot}}=\sqrt{\boldsymbol{v}_{x}^{2}+\boldsymbol{v}_{y}^{2}+\boldsymbol{v}_{z}^{2}}$

$\boldsymbol{q}_{\mathrm{tot}}=\sqrt{\boldsymbol{q}_{x}^{2}+\boldsymbol{q}_{y}^{2}+\boldsymbol{q}_{z}^{2}}$

The representative sampling volume of a TDR wave-guide depends on the geometry of the probe, essentially the geometric factor $g$. Decreasing the length of rods decreases $g$, 
making them less susceptible to electrical conductivity interference. Thus, for technical reasons, there is an optima between the accuracy of travel time measurement and conductivity losses. It is suggested for field measurement that waveguides have a length between $0.15 \mathrm{~m}$ and $0.30 \mathrm{~m}$ (Robinson et al., 2003). Besides, for the vector method in particular the following applies: The longer the wave-guides, the less sensitive the measurements will get. On the other hand, the longer the wave guides the larger the control volume for assessing the vectors. In the end ease of installation, guaranteeing correct position of the rods, was found to be decisive.

\subsection{Instrumentation}

\subsubsection{TDR wave-guides}

One TDR wave-guide consisted of two $l=0.15 \mathrm{~m}$ long, parallel stainless steel rods, $30 \mathrm{~mm}$ apart and each $5 \mathrm{~mm}$ in diameter. The TDR wave-guides were electrically connected with a $50 \Omega$ coax cable to a SDMX 50 coaxial multiplexer and further to a Campbell TDR 100 device, which generated the electrical pulses and received the signals. Both units were controlled by a Campbell CR 10x micro logger and the measurement interval was set to $90 \mathrm{~s}$ to more closely record the breakthrough of the wetting. The time resolution was the highest possible for the setup used.

We distributed ten triplets of TDR wave-guides across the hillslope, Fig. 4. The rotation symmetric head of a waveguide was attached to an aluminium pipe, whose outer diameter was smaller than the one of the probe (Fig. 3). To install wave-guides we drilled holes using a soil auger and a supporting precision tripod. We put the wave-guides into the drill holes and then pushed them into the last $15 \mathrm{~cm}$ of soil. For that we also used the tripod with its guide rail. We carefully paid attention to avoid gaps between steel rods and soil (Gregory et al., 1995) and to avoid changes in soil structure (Rothe et al., 1997). Finally, the remaining drill hole space was sealed with bentonite. The depth, $L$, of triplets (see Fig. 2) ranged between $11 \mathrm{~cm}$ (close to soil surface) and $35 \mathrm{~cm}$ (towards the boundary of soil-bedrock). A further deep installation of triplets was not possible, because there was a gradual transition from B- to C-horizon. This did not allow an installation between 35 and $40 \mathrm{~cm}$ soil depth. We located triplets in the way that sprinkled upslope contributing areas varied. Supplementary, a few oblique TDR wave-guides, called L1-L6, were installed $2-4 \mathrm{~cm}$ above the bedrock interface right into the trench face. We aligned those wave-guides within the plane formed by the $\mathrm{h}$ - and $\mathrm{y}$-axis and situated them with an angle of $45^{\circ}$ to the $\mathrm{x}$-axis. Sheet metal canopies $(20 \times 35 \times 0.4 \mathrm{~cm})$ were pushed into the soil above L1-L6, but still parallel, with a space of $10 \mathrm{~cm}$ between $L$ and the canopies. Thus, they protected each of the six waveguides against flow in z-direction. This setup allowed a direct measurement of the established lateral wetting front along the h-axis and on the bedrock interface, where SSF is likely to occur.

To calculate volumetric water content, we used the transfer function by Roth et al. (1990), who separated the impacts on the dielectric number of the wave geometry from the soil properties such as bulk density and the content of clay in organic matter. For calibration prior to the installation in the field, each wave-guide was totally submerged and the corresponding dielectric number was set equal to the volumetric water content of $1 \mathrm{~m}^{3} \mathrm{~m}^{-3}$.

\subsubsection{Sprinkling}

The entire $100 \mathrm{~m}^{2}$ hillslope segment was artificially sprinkled until SSF reached steady state. In order to account for different runoff concentration times we applied varying intensities and durations of sprinkling. We performed the following experiments: $11.5 \mathrm{~mm} \mathrm{~h}^{-1}$ for $13.08 \mathrm{~h}, 19 \mathrm{~mm} \mathrm{~h}^{-1}$ for $5 \mathrm{~h}$, $35 \mathrm{~mm} \mathrm{~h}^{-1}$ for $3.08 \mathrm{~h}$, and $56 \mathrm{~mm} \mathrm{~h}^{-1}$ for $3.5 \mathrm{~h}$ respectively. This range was achieved by different pumping pressures and two kind of systems: a sprinkler (design: Gardena) and a nozzle system by Rain Bird. Two automatic rainfall gauges, seven distributed rainfall samplers (manually checked every hour) and a water meter (sum normalized by measured sprinkling area) allowed the input to be calculated precisely. Prior to experiments we installed a vestibule around the site and also optimized the homogeneity of intensity distribution by several tests-runs. For details on the spatial distribution within the hillslope see Appendix A.

We also conducted sprinkling experiments on $1-\mathrm{m}^{2}$ subplots. These concerned triplets A-E. The rain simulator here consisted of 100 nylon tubes with inner diameters of $2 \mathrm{~mm}$, which were mounted in a $0.1 \times 0.1 \mathrm{~m}$ square pattern through a square of sheet metal of $1 \mathrm{~m} \times 1 \mathrm{~m}$. A gear moved the suspended sheet metal backwards and forwards $\pm 50 \mathrm{~mm}$ in both horizontal dimensions such that it took approximately $1800 \mathrm{~s}$ for one tube outlet to return to the same spot. Distance between releases of drops down to the soil surface was $0.5 \mathrm{~m}$. Controlled water supply was from a pump via a manifold to the tubes.

In addition, data of three natural storms were included in the analyses. The small storm on 30 May 2005 lasted 50 min with a total sum of $9.6 \mathrm{~mm}$. The rainfall on 26 October 2004 was characterised by a widely distributed amount of $12.8 \mathrm{~mm}$ during daylight hours. We classified two events with a mean intensity of $3 \mathrm{~mm} \mathrm{~h}^{-1}$. The maximum observed intensity on that day was $2.8 \mathrm{~mm}$ per $10 \mathrm{~min}$.

\subsubsection{Tracer experiments}

We carried out two kinds of tracer experiments to track SSF. First, during sprinkling application to the entire slope, Dirac delta spikes using the flourescence dyes Pyranin, Naphtionat and Uranin were fed into the sprinkler at early, mean, and late times. Flow in the hose towards the sprinkler was turbulent, 
ensuring that the tracer was well mixed by the time it reached the sprinkler or the nozzles. Tracers moved through the soil system and we took samples directly at the trench face to get tracer travel times.

Second, piezometer holes were used as two line sources of salt tracer (bromide, chloride) directly above the soil-bedrock interface at 4 and $8 \mathrm{~m}$ upslope of the trench (see Fig. 4). The tracer was quickly injected. We collected separate series of samples at the trench face (diffuse matrix flow), directly at the outlet of individual soil pipes and in summary at the tipping buckets. This allowed tracer front velocity to be calculated. It was determined by distance divided by time of first arrival minus the time of injection. Thus, it is a direct measure of presumed lateral flow along the bedrock.

Generally, the time interval of sampling was $60 \mathrm{~s}$ at the trench face and for total SSF, until flow stopped. We averaged the calculated tracer front velocities from different soil pipes in order to get mean travel times through the hillslope system.

\subsubsection{Piezometers and monitoring of flow}

The site had twelve piezometers, which reached to the bedrock at the bottom end. The inner diameter of the tube was $3 \mathrm{~cm}$. At five piezometers a pressure transducer allowed automatic readings of water levels, and eight served as the tracer source (Fig. 4). Additionally, we collected SSF in the trench by a led chamfer in the sandstone. Tipping buckets measured the SSF right next to the end of the trench. Metal sheet flow gutters allowed us to collect overland flow on the surface of the grassland hillslope. We also measured it by $100 \mathrm{ml}$ tipping buckets.

\section{Results}

A total of 123 passages of wetting fronts were recorded by TDR wave-guides. They were generated either by $1-\mathrm{m}^{2}$ subplot irrigation, entire sprinkling of the hillslope or natural rain events. Figure 5 shows a breakthrough of wetting at the TDR wave-guides of one triplet. For all data the increase in soil moisture averaged to $6.2 \% \mathrm{vol}$. We analysed the rise of $\theta(t)$ between $\theta_{\text {ini }}$ and $\theta_{\max }$ by linear regressions. The coefficients of determination, $R^{2}$, exceeded 0.9 for 66 wetting fronts and we approximate constant wetting front velocities for the progressing wetting front. We ignored 21 wetting fronts, as they were not a complete set of the three components. Thus, we used the increasing wetting phase for the assessment of $\boldsymbol{v}$ and $\boldsymbol{q}$ (according to Eqs. 1 and 2). From the total number of velocities at the TDR wave-guides, 34 datasets on triplets (equal to 102 single velocities) were finally derived. To enhance readability velocities are reported in $\mathrm{mm} \mathrm{min}^{-1}$. Table 1 lists the components of the vectors that are described by the means $\boldsymbol{v}_{x}=16.1 \mathrm{~mm} \mathrm{~min}^{-1}, \boldsymbol{v}_{y}=$ for $-0.2 \mathrm{~mm} \mathrm{~min}^{-1}$, and $\boldsymbol{v}_{z}=11.9 \mathrm{~mm} \mathrm{~min}^{-1}$.

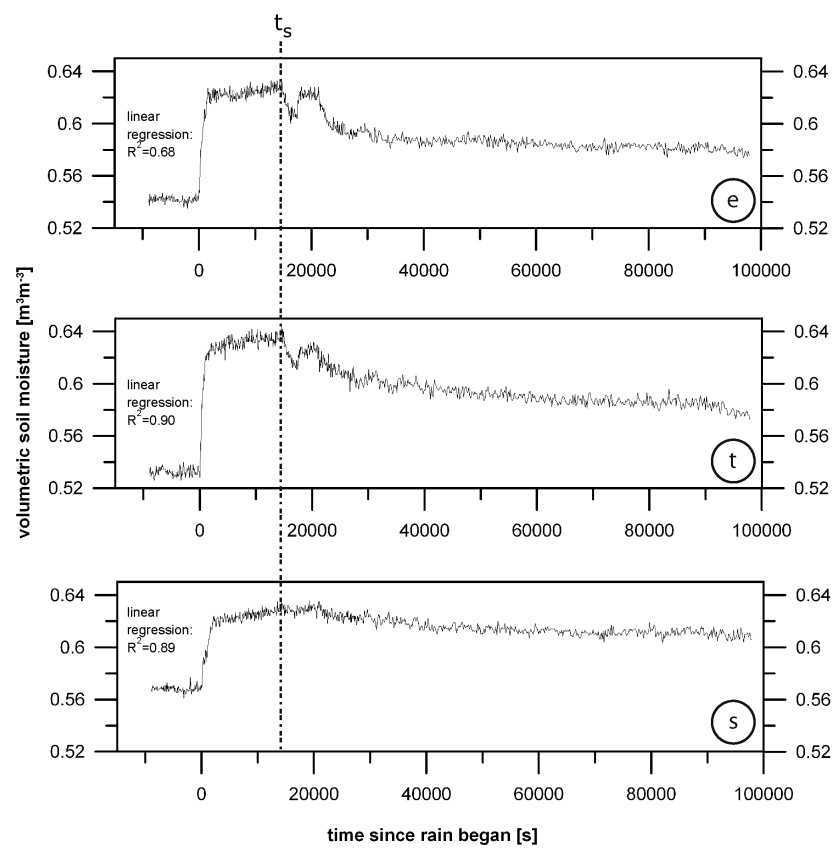

Fig. 5. Time-series of volumetric soil moisture for the three TDR wave-guides $e, t$, and $s$ of triplet $\mathrm{E}$ in $11 \mathrm{~cm}$ depth on 27/05/2005 (ID \#15). A continual, linear increase of soil moisture between $\theta_{\text {ini }}$ and $\theta_{\max }$ is assumed. The analysed coefficients of determination for these slopes are mentioned next to the graphs.

The velocity of wetting within the soil are six orders of magnitude faster than in the underlying bedrock. This shift of velocities caused water to accumulate at the soil bedrock interface. Water generated lateral flowpaths on the sloping bedrock interface within the hillslope.

Vectors of the triplets A, B, and C from repeated $1-\mathrm{m}^{2}$ subplot sprinkling events on equal intensities were analyzed by paired sample t-tests. Since the significant value for all three cases is around 0.29 , we conclude that the results are reproducible for the same sprinkling intensities and thus no change in xz-direction occurred.

Correlations between the different depths of the triplets and vector sum $v_{\text {tot }}$ were not detectable $\left(R^{2}=0.42, n=33\right)$. No significant relation was found between sprinkling intensity and either $v_{\text {tot }}$ for all data $\left(R^{2}=0.25, n=33\right)$ and neither one found for sprinkling intensity or the spatial orientation of the velocity vector.

Initial soil moisture conditions varied over $11 \%$ vol for all data and 5\%vol for all data generated by hillslope sprinkling experiments. The higher $\theta_{\text {ini }}$, the less data are available up to "wet" conditions for a precise determination of slope of $\theta(t)$ between $t_{U}$ and $t_{L}$. Thus, we got best fitting results for the slope between $t_{U}$ and $t_{L}$ when the initial hillslope system was driest (ID \#12-16). We tested correlations of $\theta_{\text {ini }}$ conditions with $v_{\text {tot }}$ and also with the amount of soil moisture increase during infiltration. For both cases no significant correlations were found. 
Table 1. Components of velocities and volume flux densities in xyz-space for triplets during different sprinkling.

\begin{tabular}{|c|c|c|c|c|c|c|c|c|c|c|c|c|c|}
\hline \multirow[t]{2}{*}{ ID \# } & \multirow[t]{2}{*}{ Date } & \multirow[t]{2}{*}{$\begin{array}{l}\text { Type of } \\
\text { sprinkling }\end{array}$} & \multirow[t]{2}{*}{$\begin{array}{l}\text { Intensity } \\
{\left[\mathrm{mm} \mathrm{h}^{-1}\right]}\end{array}$} & \multirow[t]{2}{*}{ Triplet } & \multirow[t]{2}{*}{$\begin{array}{l}\text { Depth of TDR triplet } \\
\qquad[\mathrm{cm}]\end{array}$} & \multicolumn{4}{|c|}{$\begin{array}{l}\text { Velocity of wetting front } \\
\qquad\left[\mathrm{mm} \mathrm{min}^{-1}\right]\end{array}$} & \multicolumn{4}{|c|}{$\begin{array}{l}\text { Volume flux density } \\
\qquad\left[\mathrm{mm} \mathrm{min}^{-1}\right]\end{array}$} \\
\hline & & & & & & $V_{x}$ & $V_{y}$ & $V_{z}$ & $V_{\text {tot }}$ & $q_{x}$ & $q_{y}$ & $q_{z}$ & $Q_{\text {tot }}$ \\
\hline 1 & $03 / 11 / 2004$ & hillslope & 11.5 & A & 35 & 1.5 & -0.2 & 0.4 & 1.6 & 0.8 & -0.1 & 0.2 & 0.9 \\
\hline 2 & $03 / 11 / 2004$ & hillslope & 11.5 & B & 28 & 6.8 & 0.3 & 1.8 & 7.0 & 3.8 & 0.1 & 1.0 & 3.9 \\
\hline 3 & $03 / 11 / 2004$ & hillslope & 11.5 & $\mathrm{C}$ & 28 & 2.9 & -0.6 & 1.2 & 3.2 & 1.7 & -0.3 & 0.7 & 1.9 \\
\hline 4 & $03 / 11 / 2004$ & hillslope & 11.5 & $\mathrm{D}$ & 40 & 3.3 & -0.2 & 1.5 & 3.7 & 1.9 & -0.1 & 0.8 & 2.1 \\
\hline 5 & $03 / 11 / 2004$ & hillslope & 11.5 & $\mathrm{E}$ & 11 & 8.9 & 4.2 & 1.7 & 10.0 & 2.0 & -0.5 & 1.6 & - \\
\hline 6 & $03 / 11 / 2004$ & hillslope & 11.5 & $\mathrm{~F}$ & 28 & 3.4 & -0.8 & 2.5 & 4.3 & 5.8 & -1.3 & 2.8 & 2.6 \\
\hline 7 & $03 / 11 / 2004$ & hillslope & 11.5 & $\mathrm{~K}$ & 15 & 10.1 & -2.1 & 5.2 & 11.5 & 1.2 & -0.3 & 0.2 & 6.5 \\
\hline 8 & $03 / 11 / 2004$ & hillslope & 11.5 & $\mathrm{~J}$ & 28 & 1.0 & 0 & 0.5 & 1.0 & 6.7 & 1.1 & 0.5 & - \\
\hline 9 & $12 / 11 / 2004$ & hillslope & 19 & A & 35 & 2.1 & -0.5 & 0.5 & 2.2 & 14.3 & -7.8 & 24.9 & 1.2 \\
\hline 10 & $12 / 11 / 2004$ & hillslope & 19 & B & 28 & 12.0 & 2.0 & 1.0 & 12.2 & 17.3 & -1.6 & 14.8 & 6.8 \\
\hline 11 & $12 / 11 / 2004$ & hillslope & 19 & $\mathrm{E}$ & 11 & 24.0 & -13.4 & 42.9 & 51.0 & 18.4 & 1.8 & 3.0 & 29.8 \\
\hline 12 & $27 / 05 / 2005$ & hillslope & 56 & A & 35 & 31.0 & -2.9 & 26.5 & 40.9 & 11.6 & -1.8 & 9.1 & 22.8 \\
\hline 13 & $27 / 05 / 2005$ & hillslope & 56 & B & 28 & 32.6 & 3.2 & 5.6 & 33.3 & 24.0 & -15.9 & 54.4 & 18.8 \\
\hline 14 & $27 / 05 / 2005$ & hillslope & 56 & $\mathrm{C}$ & 28 & 20.1 & -3.1 & 15.2 & 25.4 & 50.1 & 21.7 & 23.2 & 14.8 \\
\hline 15 & $27 / 05 / 2005$ & hillslope & 56 & $\mathrm{E}$ & 11 & 38.4 & -25.6 & 86.8 & 98.3 & 3.4 & -0.9 & 1.5 & 61.6 \\
\hline 16 & $27 / 05 / 2005$ & hillslope & 56 & $\mathrm{~K}$ & 15 & 89.2 & 34.8 & 38.6 & 103.2 & 4.4 & 0.4 & 2.6 & 59.3 \\
\hline 17 & $20 / 05 / 2005$ & $1 \mathrm{~m}^{2}$ & 35 & A & 35 & 6.2 & -1.6 & 2.8 & 7.0 & 3.8 & 0.5 & 0.8 & 3.8 \\
\hline 18 & $13 / 05 / 2005$ & $1 \mathrm{~m}^{2}$ & 35 & A & 35 & 8.1 & 0.8 & 4.7 & 9.4 & 5.2 & -1.6 & 1.4 & 5.1 \\
\hline 19 & $13 / 05 / 2005$ & $1 \mathrm{~m}^{2}$ & 35 & B & 28 & 6.7 & 0.9 & 1.5 & 7.0 & 2.4 & -1.3 & 2.8 & 3.9 \\
\hline 20 & $20 / 05 / 2005$ & $1 \mathrm{~m}^{2}$ & 35 & $\mathrm{C}$ & 28 & 8.8 & -2.9 & 2.4 & 9.5 & 11.5 & 0.1 & 12.8 & 5.6 \\
\hline 21 & $07 / 06 / 2005$ & $1 \mathrm{~m}^{2}$ & 55 & A & 35 & 4.4 & -2.3 & 5.2 & 7.2 & 3.7 & -0.3 & 2.1 & 3.9 \\
\hline 22 & $07 / 06 / 2005$ & $1 \mathrm{~m}^{2}$ & 55 & $\mathrm{C}$ & 28 & 20.8 & 0.2 & 21.8 & 30.2 & 12.3 & -1.6 & 3.4 & 17.2 \\
\hline 23 & $16 / 07 / 2005$ & $1 \mathrm{~m}^{2}$ & 80 & A & 35 & 7.0 & -0.5 & 4.0 & 8.1 & 6.6 & 0.4 & 2.7 & 4.3 \\
\hline 24 & $16 / 07 / 2005$ & $1 \mathrm{~m}^{2}$ & 35 & B & 38 & 22.2 & -3.1 & 6.8 & 23.4 & 21.6 & 4.2 & 13.5 & 12.8 \\
\hline 25 & $16 / 07 / 2005$ & $1 \mathrm{~m}^{2}$ & 56 & $\mathrm{C}$ & 28 & 11.8 & 0.8 & 5.3 & 12.9 & 0.8 & -0.1 & 0.2 & 7.1 \\
\hline 26 & $16 / 07 / 2005$ & $1 \mathrm{~m}^{2}$ & 80 & $\mathrm{E}$ & 11 & 35.9 & 7.1 & 23.6 & 43.6 & 3.8 & 0.1 & 1.0 & 25.8 \\
\hline 27 & $30 / 05 / 2005$ & Natural rain event & 11.5 & $\mathrm{E}$ & 11 & 14.5 & -2.5 & 13.1 & 19.7 & 8.6 & -1.4 & 7.7 & 11.6 \\
\hline 28 & $24 / 05 / 2005$ & Natural rain event & 7 & B & 28 & 5.9 & -1.5 & 1.9 & 6.3 & 3.2 & -0.8 & 1.0 & 3.5 \\
\hline 29 & $26 / 10 / 2004$ & Natural rain event & see text & A & 35 & 0.9 & -0.1 & 0.6 & 1.1 & 0.5 & 0.03 & 0.3 & 0.6 \\
\hline 30 & $26 / 10 / 2004$ & Natural rain event & see text & B & 28 & 2.3 & -0.2 & 0.7 & 2.5 & 1.3 & -0.1 & 0.4 & 1.3 \\
\hline 31 & $26 / 10 / 2004$ & Natural rain event & see text & $\mathrm{C}$ & 28 & 77.0 & -25.2 & 29.5 & 86.2 & 43.1 & -13.7 & 16.3 & 48.0 \\
\hline 32 & $26 / 10 / 2004$ & Natural rain event & see text & $\mathrm{E}$ & 11 & 1.5 & -0.4 & 1.0 & 1.8 & 0.9 & -0.2 & 0.6 & 1.1 \\
\hline 33 & $26 / 10 / 2004$ & Natural rain event & see text & B & 28 & 3.0 & -0.1 & 2.8 & 4.1 & 1.7 & 0.05 & 1.4 & 2.2 \\
\hline 34 & $26 / 10 / 2004$ & Natural rain event & see text & $\mathrm{C}$ & 28 & 23.0 & -1.5 & 2.9 & 23.2 & 13.3 & -0.8 & 1.7 & 13.4 \\
\hline
\end{tabular}

The time series of $\theta$ after sprinkling showed an extended tailing of up to 4 days until initial soil moisture conditions were reached again. This pattern was more dominant for deep triplets and for the experiments in November (ID \#111), when transpiration was negligible. The long-tailed pattern is shown in Fig. 5.

An overview of all vectors is given by 2-D hillslope slices (Fig. 6). The results are plotted in a linear scale, although dimensions differ over two orders of magnitude.

4.1 Analysis of $\mathrm{x}-\mathrm{y}$ - $\mathrm{z}$-velocity components during infiltration towards the spatially dominant direction

Of main interest is the view in the y-direction of contours i.e., looking at the $\mathrm{x}-\mathrm{z}$ plane in our notation, Fig. 6a. The ID numbers and corresponding alphabetic code refer to the location of triplets on the hillslope. All vectors show a downhill component. The dominance of the $\mathrm{z}$ - against the $\mathrm{x}$-components was checked with a t-test for all data (see Table 2). A significance value of the test of 0.1 was selected because the pat- tern should trace clearly. Presuming this significance value, we could not find $\mathrm{z}$ - or $\mathrm{x}$-components dominating except for the vectors at depth $\leq-28 \mathrm{~cm}$ and $\leq-35 \mathrm{~cm}$ where the $\mathrm{x}$ components exceeded the z-components (see bold numbers). Even so, the mean angle of the resulting two vectors is $11^{\circ}$ and $18^{\circ}$ steeper than the h-axis. Thus, we do not consider the orientation of the wetting front as to be fully lateral.

The observed direction in the xy-plane (Fig. 6b) is widely aligned around $y=0$. By means of the $t$-test, a dominating $\mathrm{x}$-direction (a downhill force rather than a spreading along the contours) is proposed. This is confirmed by a strong significance value of 0.05 . The fast velocities (ID \#11, 15, 16) concerned the shallow triplets $\mathrm{K}$ and $\mathrm{E}$, where the upper end of TDR rods is situated merely in $5-10 \mathrm{~cm}$ soil depth. Thus they are are within easy reach for the wetting. Amongst fast velocities ID 12, 22 and 31 correspond to deep triplets A and C.

The yz-view (Fig. 6c) reveals the dominance in the $\mathrm{z}$ direction, which is supported by a significant value $<0.05$ (t-test). The above mentioned fast velocities at the shallow 
(a)

View in direction of contour

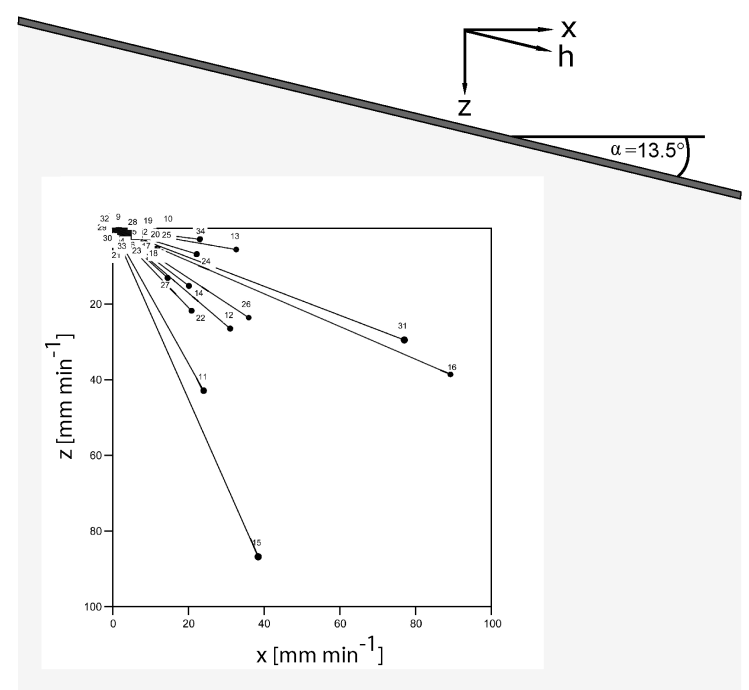

(b)

View from top down onto soil surface

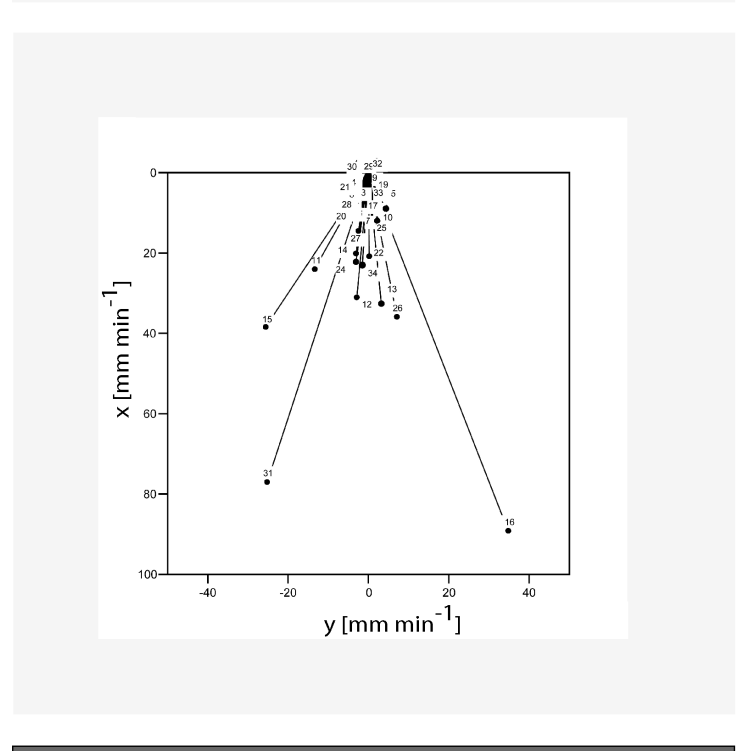

(c)

View in the direction of contour gradient

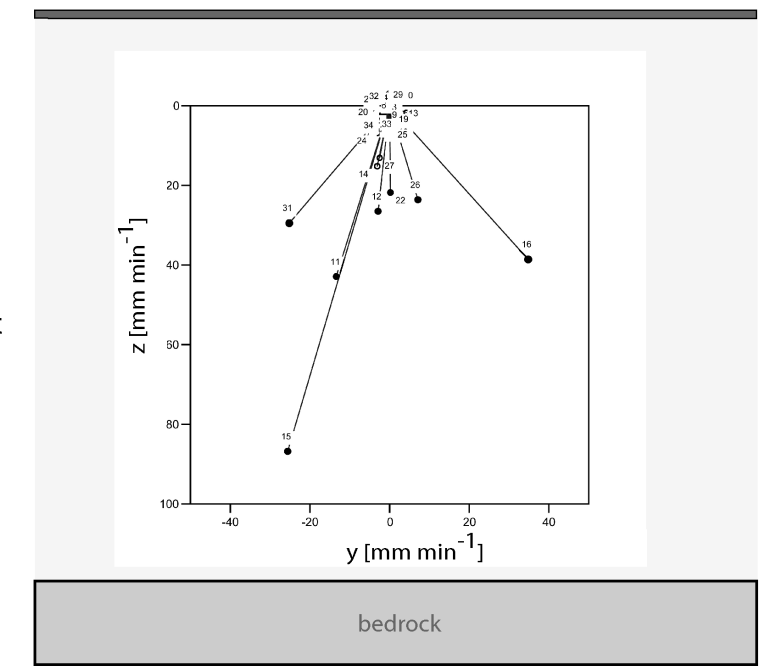

Fig. 6. Resulting velocity vectors of the wetting front at various triplets on the hillslope. Vectors are not shown in arrow format but point format. Given ID numbers refer to information provided in Table 1. The graphs are embedded in "physical" descriptions to support orientation on the different views. 
Table 2. Values of t-test to analyse $\mathrm{x}$ - and $\mathrm{z}$-components for the dominating direction of the resulting vector.

\begin{tabular}{|c|c|c|c|c|}
\hline \multirow[t]{2}{*}{ Selected triplets } & \multirow{2}{*}{$\begin{array}{l}\text { Total number } \\
\text { of vectors }\end{array}$} & \multicolumn{3}{|c|}{ t-test } \\
\hline & & Test value, $\mathrm{T}$ & $\begin{array}{l}\text { Degrees of } \\
\text { freedom, } \mathrm{df}\end{array}$ & $\begin{array}{l}\text { Sig. } \\
\text { (2-tailed) }\end{array}$ \\
\hline $\begin{array}{l}\text { All (Natural events, sprinkling of } \\
\text { hillslope, and } 1 \mathrm{~m}^{2} \text { plots ) }\end{array}$ & 34 & 1.184 & 66 & 0.241 \\
\hline Sprinkling of hillslope & 15 & 0.046 & 28 & 0.964 \\
\hline Sprinkling of all $1 \mathrm{~m}^{2}$ plots & 10 & 1.324 & 18 & 0.202 \\
\hline $\begin{array}{l}\text { Sprinkling of deep } 1 \mathrm{~m}^{2} \text { plots } \\
\mathrm{A}, \mathrm{B}, \mathrm{C}\end{array}$ & 9 & 1.551 & 16 & 0.140 \\
\hline $\begin{array}{l}\text { All data of shallow triplets } \\
\mathrm{E}, \mathrm{K}\end{array}$ & 8 & 0.116 & 14 & 0.909 \\
\hline $\begin{array}{l}\text { All data of deep triplets } \\
\text { A, B, C, D, F; where } z \geq 28 \mathrm{~cm}\end{array}$ & 25 & 1.870 & 48 & 0.068 \\
\hline $\begin{array}{l}\text { Sprinkling of deepest triplets } \\
\text { A, D; where } z \geq 35 \mathrm{~cm}\end{array}$ & 8 & 2.66 & 14 & 0.019 \\
\hline
\end{tabular}

triplets also trace in this view. In summary, the wide spreading distribution along the $y$-axis is characterised by a mean velocity of $-1.1 \mathrm{~mm} \mathrm{~min}^{-1}$ and showed a coefficient of variation of -8.4 . We use the latter descriptor to characterise the heterogeneity in the soil.

As triplets B, C, F, and $\mathbf{J}$ are located at the same depth, we also addressed the question of the effects of differing upslope sprinkling area on orientation. Using data from $11 \mathrm{~mm} \mathrm{~h}^{-1}$ sprinkling, we analysed the resulting vector of the infiltration front for xz-components. The Kruskal-Wallis test (Kruskal and Wallis, 1952) indicated that the ratings of the resulting vector (its orientation towards a lateral component) did not differ with the upslope sprinkling area (chi-square $=3$, asymp. sig. $=0.392$ ).

The question of scale: do vector components for the same triplets differ between $1-\mathrm{m}^{2}$ subplot sprinkling and hillslope sprinkling? This could merely be investigated for given intensities of $55 \mathrm{~mm} \mathrm{~h}^{-1}$ and given equal antecedent soil moisture for triplets $\mathrm{A}$ and $\mathrm{C}$, where we emphasised the $\mathrm{xz}$ components. Here, we refrained from applying a test, as the sample size was too small. But from a visual check of Fig. 6 the direction of the wetting front changed moderately between the two types of sprinkling.

The lateral vectors of SSF at the trench face were analysed on the basis of the mean average of L1 to L5. For the $1-\mathrm{m}^{2}$ subplot sprinkling events ID \#21,22 it amounted to $2.5 \mathrm{~mm} \mathrm{~min}^{-1}$. And for the entire hillslope event on 14 June 2005 the front velocity was calculated to $4.6 \mathrm{~mm} \mathrm{~min}^{-1}$.

\subsection{Time to concentration of runoff and tracer travel times}

SSF, initiated by sprinkling, flowed into the trench through up to nine soil pipes. Except two (where L2 and L3 were installed) all flow pathways where not visible until the first runoff indicated an active pipe. These horizontal preferen- tial pathways contributed almost the total SSF. As proved by visual observations very little percolation out of the matrix occurred. Pipe outlets were located close to the soil-bedrock interface showing the existence of microchannels according to Sidle et al. (2001). The same soil pipes were repeatedly active. The characteristics of the SSF as time to concentration and mean tracer velocity are shown in Table 3. Time to concentration of SSF, calculated as lag time between start of sprinkling to start of SSF, varied between 43 and $120 \mathrm{~min}$. It depended on sprinkling intensity $\left(R^{2}=0.98\right)$. Table 3 also shows the accumulated charge of sprinkling (initial loss) until SSF occurred. We detected a weak proportionality with sprinkling intensity.

During sprinkling five Dirac delta pulses of tracer allowed travel times to be measured from the first tracer arrival at the trench face. For saturated conditions, as indicated by the piezometers, it amounted to around 7 min (Table 3). Thus, tracer travel times during wet conditions and active runoff at the trench were 5 to 10 times faster than initial time to concentration of flow. During almost initial conditions on 14 June 2005 when one tracer was fed into sprinkling $20 \mathrm{~min}$ past start of sprinkling, the tracer travel time was $80 \mathrm{~min}$, which was similar to the time to concentration $(74 \mathrm{~min})$.

Line source salt tracer experiments at a distance of $8 \mathrm{~m}$ from the trench were carried out, when piezometers indicated saturated conditions $(10-15 \mathrm{~cm})$ above the bedrock interface. The tracer front velocity was $658 \mathrm{~mm} \mathrm{~min}^{-1}$. For the same conditions tracer front velocity for the $4 \mathrm{~m}$ tracer line amounted to $375 \mathrm{~mm} \mathrm{~min}^{-1}$.

We also calculated volume flux densities according to Eq. (2) which also resulted in a three-dimensional vector. This was needed to get the vector sum $q_{\mathrm{tot}}$, which ranges between 0.9 and $61.6 \mathrm{~mm} \mathrm{~min}^{-1}$ (Table 1). The mean value of $q_{\mathrm{tot}}$ is $13.4 \mathrm{~mm} \mathrm{~min}^{-1}$. 
Table 3. Characteristics on the generation of subsurface stormflow (SSF) and results of tracer applications.

\begin{tabular}{|c|c|c|c|c|c|c|}
\hline & $03 / 11 / 2004$ & $12 / 11 / 2004$ & $27 / 05 / 2005$ & $14 / 06 / 2005$ & $14 / 06 / 2005$ & $14 / 06 / 2005$ \\
\hline Sprinkling intensity $[\mathrm{mm} / \mathrm{h}]$ & 11.5 & 19 & 56 & 32 & 32 & 32 \\
\hline $\begin{array}{l}\text { Time to concentration of SSF } \\
\text { (lag time from start of sprinkling to start } \\
\text { runoff) [min] }\end{array}$ & 120 & 104 & 43 & 74 & 74 & 74 \\
\hline $\begin{array}{l}\text { Accumulated amount of sprinkling until } \\
\text { start of SSF [mm] }\end{array}$ & 23 & 33 & 40 & 41 & 41 & 41 \\
\hline Tracer application by sprinkling & & & & & & \\
\hline $\begin{array}{l}\text { Time of tracer input, Dirac spike } \\
\text { [min since start of sprinkling] }\end{array}$ & 238 & - & 109 & 50 & 105 & 152 \\
\hline $\begin{array}{l}\text { Time of first arrival } \\
\text { [min since start of sprinkling] }\end{array}$ & 251 & - & 116 & 130 & 137 & 158 \\
\hline $\begin{array}{l}\text { Time of max. concentration } \\
\text { [min since start of sprinkling] }\end{array}$ & 257 & - & 128 & 135 & - & - \\
\hline $\begin{array}{l}\text { Travel time of tracer, input until first } \\
\text { arrival [min] }\end{array}$ & 7 & - & 8 & 80 & 22 & 6 \\
\hline $\begin{array}{l}\text { Degree of saturation for lower hillslope } \\
\text { segment (point measurements at } 40 \mathrm{~cm} \\
\text { depth, piezometers) at moment of tracer } \\
\text { application } \\
\text { Tracer line source at piezometers }\end{array}$ & full & - & full & little & less & full \\
\hline $\begin{array}{l}\text { Time of tracer input } \\
\text { [min since start of sprinkling] }\end{array}$ & 240 & - & 110 & - & - & - \\
\hline
\end{tabular}

\subsection{Water balance calculations}

The water balance in Table 4 summarizes that the input for the three sprinkling experiments varied between 97.5 and $199 \mathrm{~mm}$. Overland flow was $2.2 \mathrm{~mm}$ for the small sprinkling intensity and reached $53.4 \mathrm{~mm}$ at the highest intensity. In contrast SSF decreased with increasing sprinkling intensity. We quantified losses between 22.5 and $62 \mathrm{~mm}$.

\section{Discussion}

The vectors are reproducible in repeated experiments, which is in accord with Germann and Zimmermann (2005a). The direction of the vectors also matches well with the data of the previous study. The velocities of both experiments show the same magnitude, although soils are different. The bending of vectors, due to the considerable amount of soil moisture from the run 1 or 2 days before, which Germann and Zimmermann (2005a) showed, could not be observed in these data. This is because repeatable sprinkling events here were far apart from each other in time.

\subsection{Discussion of temporal patterns}

Here, we emphasize the discussion of temporal hillslope response, concentration times and the link to velocities calculated by the triplets. Looking at the lateral velocity of the wetting front (determined as h-component at waves-guides
Table 4. Waterbalance for sprinkling experiments.

\begin{tabular}{|c|c|c|c|}
\hline & $03 / 11 / 2004$ & $12 / 11 / 2004$ & $27 / 05 / 2005$ \\
\hline sprinkling intensity $\left[\mathrm{mm} \mathrm{h}^{-1}\right]$ & 11.5 & 19 & 56 \\
\hline Input $[\mathrm{mm}]$ & 151 & 97.5 & 199 \\
\hline Overland flow [mm] & 2.2 & 3.5 & 53.4 \\
\hline $\mathrm{SSF}[\mathrm{mm}]$ & 54 & 28 & 19.8 \\
\hline Soil storage $[\mathrm{mm}]$ & 33.2 & 43.5 & 66 \\
\hline Losses $[\mathrm{mm}]$ & 62 & 22.5 & 59.8 \\
\hline
\end{tabular}

L1-L6 and at triplets close to bedrock interface) and the travel times obtained by tracer data during steady state conditions we conclude: The lateral velocities (along h-axis) of first line source tracer arrival onto the bedrock are between 140 and 80 times higher than for the vector of wetting front. The difference is obvious as conditions shift from unsaturated to saturated for this shallow layer onto the bedrock while discharge at the trench face occurred. Note further, that we took tracer samples directly at the outlet of the soil pipes.

Our observations of temporal patterns in the unsaturated zone are different from rapid pore pressure responses and the direct control of timing and magnitude of peak discharge (Torres et al., 1998). 


\subsection{Uncertainties and limitations involved in the approach}

A major concern in the application of this approach at the Lutertal field site is the dominating runoff generation mechanism. The lateral SSF is delivered by preferential flow in soil pipes occurring at the trench face. For the z-direction we mentioned existing vertical macropores within the sandy loam B-horizon. Thus vertical infiltration, is a combination of preferential pathways and homogenous matrix infiltration. It is likely that water bypassed the wave-guides with their lengths $l$ of $15 \mathrm{~cm}$. In this exercise we showed that 21 out of 123 passages of wetting fronts wetting were excluded and concerned some kind of preferential flow pattern. Up to now, the length of the TDR wave guide has not been changed. We will work on that task in upcoming investigations in order to sufficiently trace preferential flowpaths.

The results presented concern the moment of initial infiltration and the first wetting of soil. They provide evidence for "bending of flow" from a vertical to a lateral component, which was seen in Table 2, last row. But an obvious lateral vector, aligned on the h-axis is not supported by the data. We may further question: a.) Why was there no significant change of h-components as the upslope contributing area (catchment area) increased and b.) why was there a minor dominance in $\mathrm{x}$ - or $\mathrm{h}$-direction for deep triplets, although SSF occurred? To answer these questions we must highlight the fact that lateral flow is delayed with respect to infiltration. And second, after the infiltration front passed by, the system shifted to saturated conditions. For this point the TDR technique in general does not allow extraction of any further information on the volume of flux passing by. This is a major restriction of the vector method.

In order to compare average volume flux density $\boldsymbol{q}$ by the TDR wave-guides with discharge data from the trench, we assessed the representative elementary cross-sectional area (RECA). A discussion on that was introduced by Germann and Zimmermann (2005a) who determined the bottom area of the truncated tetrahedron to $0.02 \mathrm{~m}^{2}$. The sampling volume of TDR wave-guides is widely modelled by numerical approaches (Ferré et al., 1998; Ferré et al., 2001) which may help to get a cross sectional area corresponding to the volume flux density of the triplet. In a first assumption the projection of the TDR rods might be used. Comparisons between $\boldsymbol{q}$ at the triplets and a calculated flux density at the trench face $\left(16 \times 0.45 \mathrm{~m}^{2}\right)$ for steady state SSF stress the time scales of both measures.

\subsection{Further steps}

Concluding the last sections we see a need to verify the approach presented here and quantitatively link it to discharge data. One useful option to elucidate this is a flow transport model. This would allow comparing the velocity information at triplets and the SSF gauging with the modeled numbers of both measures. On the other hand, the data provided in this work focuses on the wetting front. For this, kinematic wave approximations for subsurface flow in hillslopes are simple but efficient solutions. Here, we see an useful link to the work of Cabral et al. (1992) who showed in their Fig. 2 the dimensional analysis of unsaturated flow and its $\mathrm{x}, \mathrm{z}$, and volume flux-vectors.

Further, to gain understanding of postponed lateral flow and recorded bending of flow, we must extend the approach and integrate data from the decreasing limb of soil moisture. For the steady state experiments performed, the shape of the recession limb did not allow us to extract more information because of the long tailing of $\theta$.

\section{Conclusions}

We could find the following answers to our questions:

i.) Vertical infiltration and its propagating fronts do not move truly vertically, as we have shown in this exercise. None of the vectors was an exclusive z-component. Soil heterogeneity causes deviation up to an angle of $67^{\circ}$ from the z-axis.

ii.) The approach presented allowed us to determine the spatial direction of the advancing wetting front. This is restricted to the first passage of the wetting front! Thus, up to now the approach is insufficient to fully demonstrate the "bending of flow" because there is a time delay between infiltration and the lateral components. However, several deep triplets provide evidence for lateral components as discussed above.

iii.) For the Lutertal field site we gained knowledge that lateral saturated tracer movements on top of the bedrock are 25-140 times faster than lateral unsaturated zone velocities of the wetting front. The vector velocities ranged in from 0.1 to $89 \mathrm{~mm} \mathrm{~min}^{-1}$. Time to concentration was sprinkling rate dependent and ranged between 43 and 120 min for the site. No significant relation was found between concentration time and lateral velocity or the vector sum $v_{\text {tot }}$.

iv.) This method is restricted to non-complex substrate (skeleton or portion of big stones) to install TDR waveguides. A plane bedrock topography with its similarity to the simple surface topography is of further help. This method is restricted to the first wetting front arriving while sprinkling or a rain storm occurs. The uncertainty of this method, e.g. dominance of preferential pathways during runoff, questions the transferability of $l=15 \mathrm{~cm}$ wave-guide information towards a hillslope of $100 \mathrm{~m}^{2}$. Quantitative comparisons between measured outflow at the trench and volume flux at the triplet are not possible to date. We believe that there is useful information included, but there is a need to extend the approach. 


\section{Appendix A}

Sprinkling intensity measured by seven randomly, spatially distributed point measurements on the hillslope. Mean and standard deviation of the data are provided in the lower right corner. Data concern the experiment on 3 November 2004.

\begin{tabular}{|c|c|c|c|c|c|c|c|c|c|c|c|c|}
\hline \multirow{2}{*}{$\frac{\text { Sampler }}{1}$} & \multicolumn{12}{|c|}{ Sprinkling intensity $\left[\mathrm{mm} \mathrm{h}^{-1}\right]$ for $1 \mathrm{~h}$ of sprinkling while entire experiment } \\
\hline & 10 & 5 & 3 & 13 & 10 & 13 & 15 & 17 & 18 & 11 & 12 & 8 \\
\hline 2 & 11 & 9 & 9 & 13 & 10 & 13 & 13 & 10 & 11 & 13 & 9 & 8 \\
\hline 3 & 11 & 10 & 14 & 12 & 9 & 12 & 9 & 8 & 9 & 0 & 7 & 9 \\
\hline 4 & 14 & 16 & 18 & 18 & 15 & 24 & 24 & 23 & 35 & 24 & 17 & 12 \\
\hline 5 & 10 & 11 & 10 & 13 & 10 & 10 & 10 & 10 & 12 & 11 & 9 & 4 \\
\hline 6 & 10 & 8 & 11 & 13 & 9 & 10 & 9 & 9 & 12 & 9 & 5 & 9 \\
\hline \multirow[t]{3}{*}{7} & 10 & 8 & 10 & 10 & 8 & 8 & 10 & 9 & 11 & 11 & 8 & 13 \\
\hline & & & & & & & & & & mean & \multicolumn{2}{|c|}{11.5} \\
\hline & & & & & & & & & & stdder & \multicolumn{2}{|c|}{4.6} \\
\hline
\end{tabular}

Acknowledgements. We highly appreciated the input of I. Hincapié. F. Schärer guaranteed access to the research site and helped with useful farming support. Our study benefited from discussions with F. Naef who also contributed financial support. This project was funded by the Swiss National Research Foundation (\#200020101562)

Edited by: K. Bishop

\section{References}

Anderson, M. G. and Burt, T. P.: The role of topography in controlling throughflow generation, Earth Surface Processes and Landforms, 3, 331-344, 1978.

Beven, K. and Germann, P.: Macropores and waterflow in soils, Water Resour. Res., 18, 1311-1325, 1982.

Buttle, J. M. and McDonald, D. J.: Coupled vertical and lateral preferential flow on a forested slope, Water Resour. Res., 38, WR000773, 2002.

Cabral, M. C., Garrote, L., Bras, R. L., and Entekhabi, D.: A kinematic model of infiltration and runoff generation in layered and sloped soils, Adv. Water. Res., 15, 311-324, 1992.

Ferré, P. A., Knight, J. H., Rudolph, D. L., and Kachanoski, R. G.: The sample areas of conventional and alternative time domain reflectometry probes, Water Resour. Res., 34, WR02093, 1998.

Ferré, P. A., Nissen, H. H., Moldrup, P., and Knight, J. H.: The sample area of time domain reflectometry probes in proximity to sharp dielectric permittivity boundaries, p. 195-209, in: 2nd Proc. Int. Symp. and Workshop on Time Domain Reflectometry for Innovative Geotechnical Applications, edited by: Dowding, C. H., available online: http://www.iti.northwestern.edu/tdr/ tdr2001/proceedings/Final/TDR2001.pdf (verified 15/07/2005), Infrastructure Technology Institute, Northwestern University, Evanston, IL, 2001.

Germann, P. F., Jäggi, E., and Niggli, T.: Rate, kinetic energy and momentum of preferential flow estimated from in situ water content measurements, Europ. J. Soil Sci., 53, 607-617, 2002.

Germann, P. F. and Zimmermann, M.: Directions of preferential flow in a hillslope soil, Quasi-steady flow, Hydrol. Processes, 19, 887-899, 2005a.
Germann, P. F. and Zimmermann, M.: Water balance approach to the in situ estimation of volume flux densities using slanded TDR wave guides, Soil Sci., 170(1), 3-12, 2005b.

Gregory, P. J., Roland, P., Eastham, J., and Micin, S.: Use of time domain reflectometry (TDR) to measure the water content of sandy soils, Aust. J. Soil Res., 33, 265-276, 1995.

Greminger, P.: Physikalisch-ökologische Standortsuntersuchung über den Wasserhaushalt im offenen Sickersystem Boden unter Vegetation am Hang, Eidg. Anstalt forstl. Versuchswes. Mitt., 60, 151-301, 1984.

Harr, R. D.: Water flux in soil and subsoil on a steep forested slope, J. Hydrol., 33, 37-58, 1977.

Koyama, K. and Okumura, T.: Process of pipeflow runoff with twice increase in discharge for a rainstorm, Trans. Jpn. Geomorphol. Union, 23, 561-584, 2002.

Kruskal, W. H. and Wallis, W. A.: Use of ranks in one-criterion variance analysis, J. Amer. Stat. Assoc., 47(260), 583-621, 1952.

Robinson, D. A., Jones, S. B., Wraith, J. M., Or, D., and Friedman, S. P.: A Review of Advances in Dielectric and Electrical Conductivity Measurement in Soils Using Time Domain Reflectometry, Vadose Zone J., 2, 444-475, 2003.

Roth, K., Schulin, R., Flühler, H., and Attinger, W.: Calibration of time domain reflectometry for water content measurements using a composite dielectric approach, Water Resour. Res., 26, WR01238, 2267-2274, 1990.

Rothe, A., Weis, W., Kreutzer, K., Matthies, D., Hess, U., and Ansorge, B.: Changes in soil structure caused by the installation of time domain reflectometry probes and their influence on the measurement of soil moisture, Water Resour. Res., 22, WR0474, 1585-1594, 1997.

Sherlock, M. D., Chappell, N. A., and McDonnell, J. J.: Effects of experimental uncertainty on the calculation of hillslope flow paths, Hydrol. Processes, 14, 2457-2471, 2000.

Sidle, R.C., Noguchi, S., Tsuboyama, Y., and Laursen, K.: A conceptual model of preferential flow systems in forested hillslopes: evidence of self-organization, Hydrol. Processes, 15, 1675-692, 2001.

Sidle, R.C., Tsuboyama, Y., Noguchi, S., Hosoda, I., Fujieda, M., and Shimizu, T.: Storm flow generation in a steep forested headwater: a linked hydrogeomorphic paradigm, Hydrol. Processes, 14, 369-384, 2000. 
Torres, R., Dietrich, W. E., Montgomery, D. R., Anderson, S. P., and Loague, K.: Unsaturated zone processes and the hydrologic response of a steep unchanneled catchment, Water Resour. Res., 23, WR01140, 1865-1879, 1998.

Uchida, T., Tromp-van Meerveld, I., and McDonnell, J. J.: The role of lateral pipe flow in hillslope runoff response: an intercomparison of non-linear hillslope response, J. Hydrol., 311, 117-133, 2005 .
Weyman, D. R.: Measurements of the downslope flow of water in a soil, J. Hydrol., 20, 267-288, 1973.

Wheater, H. D., Langan, S. J., Miller, J. D., and Ferrier, R. C.: The determination of hydrological flow paths and associated hydrochemistry in forested catchments in central Scotland, IAHS Pub. No. 167, Proc. Vancouver Symposium, 1987. 